\title{
Detection of atmospheric urban heat island through direct measurements in Cluj-Napoca city, Romania
}

\author{
Ioana HERBEL, Adina-Eliza CROITORU, Ionuț RUS, Gabriela Victoria HARPA and \\ Antoniu-Flavius CIUPERTEA ${ }^{1}$
}

\begin{abstract}
In the last decades, cities worldwide have experienced accelerated development, so that continuous urbanization and its impact is presently one of the most important topics in different fields of research. The main aim of this study is to identify the intensity of the atmospheric urban heat island in Cluj-Napoca city, through direct observations campaigns by using fixed points and transect measurements. The data has been collected over a period of 6 months (May-October 2015). The measurements have been performed mainly in anti-cyclonic weather condition, during the night, between 23:00 and 03:00. The profiles trajectories followed the main roads of the city on directions North-South, East-West, and Northwest-Southeast. 8 fixed points have been chosen in order to highlight best the temperature patterns in different Local Climate Zones (LCZs). The main findings of the study are the followings: the direct observations performed in three seasons (spring, summer and autumn) revealed the existence of an atmospheric urban heat island in Cluj-Napoca city; the warmest areas are compact high-rise and compact midrise, located in the eastern half of the city, where the temperature increases by more than $2.0^{\circ} \mathrm{C}$, as average value for all campaigns, but the maximum values, recorded in the summer are higher than $3.0^{\circ} \mathrm{C}$; the coolest areas are sparsely built areas and the large low-rise/water areas, where the temperature is quite similar to that recorded in the nearby rural areas (difference of $0.0-0.1^{\circ} \mathrm{C}$, as average values); local factors, such as mountain breeze and topography have a great impact on the atmospheric urban heat island configuration.
\end{abstract}

Keywords: atmospheric urban heat island, direct measurements, Cluj-Napoca, Romania

\section{Introduction}

In the last decades, cities worldwide have experienced accelerated development, so that continuous urbanization is presently one of the most important dimensions of contemporary global change. Today 54 percent of the world's population lives in urban areas and it is responsible for 76 percent of the energy consumption and greenhouse gas emissions (Grubler, A. et al. 2012). Moreover, the urban population is expected to increase to 66 percent by 2050 (United Nations, 2014). This fact implies expanding urban land use and a massive demand for built-up areas should be anticipated in the next few decades (SETO,
K.C. et al. 2012; Song, X-P. et al. 2016). In Europe alone, at present, nearly 73 percent of the population lives in cities and it is projected to reach 82 percent by 2020 (European Environment Agency, 2010; АкваRI, H. et al. 2016).

Beside the positive aspects of this process, such as increasing the frost-free period or income from better paid jobs, the environmental impact of urbanization is nowadays a major problem discussed in urban planning and development studies. One of the most important consequences of the urbanisation process is the intensification of urban heat island (UHI) (Herbel, I. et al. 2015). This phenomenon generates higher air and surface temperatures compared to nearby rural areas and usually

\footnotetext{
${ }^{1}$ Faculty of Geography, Babeş-Bolyai University. 5-7, Clinicilor Street, 400006 Cluj-Napoca, Romania.

E-mails: ioana.herbel@yahoo.com, croitoru@geografie.ubbcluj.ro, rusionut22@gmail.com,

harpa_gabriela@yahoo.com, antonio3088@yahoo.com
} 
causes weather anomalies, a deterioration of the living environment by increasing temperatures and air pollution, by intensifying the heat waves, and even a rise in mortality (SHEPHERD, J.M. and Burian, S.M. 2003; Memon, R.A. et al. 2008; WonG, K.V. et al. 2013; UnGER, J. et al. 2014). During heat waves, inhabitants of urban areas may experience sustained thermal stress both in day-times and night-times whereas in rural areas people get some relief from thermal stress at night (UNGer, J. et al. 2014). Economically, an increase in energy consumption for cooling is associated to UHI, especially during summer time.

Under these circumstances, in the last years, many researchers in different fields such as climatology, urban planning or remote sensing, focused on urban heat environment and UHI (LI, J. et al. 2009; UNGER, J. et al. 2010; Kumar, D. and SHeKhar, S. 2015). The urban environment is a complex system, involving concentrated human activities and integrated ecosystem vulnerabilities that could be seriously affected by the intensity increase of the UHI (CoHEN, B. 2006; Hu, L. et al. 2015). An UHI can be present at any latitude, may occur during the day or night and can be detected in any season as a function of the local thermal balance. It is more intense on calm and clear days and it is highly affected by wind and precipitation (SANTAMOURIS, M. 2015; АквARI, H. et al. 2016).

UHIs have been detected in many cities of the world. Thus, by 2011, atmospheric urban heat island (AUHI) observations on 221 cities and towns from all over the world were reported in the literature (STEWART, I.D. 2011). The UHI intensity detected in several European and Mediterranean cities is more significant at night and varies between $1.5^{\circ} \mathrm{C}$ and $12.0^{\circ} \mathrm{C}$, while in other cities (e.g. Athens and Parma), maximum UHI intensity occurs during daytime (SAntamouris, M. 2007; Founda, D. et al. 2015).

The main factors generating and affecting the UHI intensity are the urban architecture, the type of urban materials, the population density, the synoptic and local meteorological conditions as well as the lack or small percent- age of green and water surfaces inside the city. Furthermore, artificial heating and cooling of buildings, transportation and industrial processes introduce anthropogenic sources of heat into the urban environment, causing distinct and even enhanced UHIs, their intensities showing an overall increase over the years (Wilby, L.R. 2007; AkbaRI, H. et al. 2016).

Cities with high population density and increased human activities, including intense individual and public transportation, experience a higher UHI intensity during daytime. In some of these cities there is a higher UHI intensity in the summer (e.g. Rome, Madrid) while in others in the winter (e.g. Lisbon). Katoulis, B.D. and Theoharatos, G.A. (1984) and Giannaros, T.M. and Melas, D. (2012) reported a higher UHI intensity in the night time and during the warm period in Thessaloniki and Athens (Greece). Maximum intensity of the daytime UHI in summer was detected in other non-European cities with subtropical or tropical climate, such as Shanghai (TAN, J. et al. 2010) or Muscat (Charabi, Y. and Bakhit, A. 2011), while in Szeged (Hungary), during a one-year long measurement campaign, the maximum intensity was found in the night-time (LELOvics, E. et al. 2014). It is concluded that reported UHI varies considerably according to existing studies in terms of maximum intensity and season/time of occurrence. In addition to the aforementioned reasons related to different climatic features and thermal balance of the cities, other reasons such as the application of different monitoring protocols or the selection of reference stations could largely influence UHI estimations (Founda, D. et al. 2015).

Despite the large number of studies conducted worldwide, in Romania only a few studies have been performed on UHIs until now. For Bucharest, several studies were conducted by using direct measurements data and satellite imagery (Cheval, S. et al. 2009; Cheval, S. and Dumitrescu, A. 2009, 2015). For Iaşi, direct measurements were performed in the '60s and '70s (Gugiuman, I. 1967; ERHAN, E. 1971, 1979), while recently the research topic in the same city was re- 
assumed by Apostol, L. et al. (2012). For Cluj-Napoca only one study focused on the surface urban heat island based on Landsat imagery (ImbroAne, A.M. et al. 2014).

The main aim of this study is to identify the intensity of atmospheric UHI in Cluj-Napoca city, through direct observations campaigns by using fixed points and transect measurements.

\section{Materials and methods}

\section{Study area}

Cluj-Napoca is the second most populated city in Romania after the capital city Bucharest and the largest and most populated urban centre in Central Romania (Transylvania). The city is located among three major geographical units (Apuseni Mountains - the northern part of Western Carpathians -, Someşan Plateau and Transylvania Plain). Cluj-Napoca extends over $179.5 \mathrm{~km}^{2}$ and the population exceeds 320,000 inhabitants.

The city is crossed over from West to East by Someşul Mic River over a length of $16 \mathrm{~km}$. The urban area (located between 300 and $400 \mathrm{~m}$ a.s.l.) sprawls along its valley, generating the dominant air flow inside the city. The urban area expansion is limited by the topography which consists mainly of hills up to $1,000 \mathrm{~m}$.

The general climate of the region is continental with western oceanic influences. The dominant concrete and asphalt landscape is the result of the intense urbanization process during the communist era, when neighbourhoods with high-density blocks of flats were built in the peripheral areas of the city. However, this process did not affect the historical centre, dominated by $18^{\text {th }}$ and $19^{\text {th }}$ century buildings with massive baroque architecture.

\section{Data used}

The literature on heat islands reports five methods commonly used for the evaluation of this phenomenon: fixed stations/points, mobile transverse, remote sensing, vertical sensing, and energy balances (Gartland, L. 2008). Air temperature is usually measured at about 1.5 meters above the ground. In the areas where measurements in fixed stations are not available, the field campaigns and transects studies involve the use of hand-held measurement devices or mounting measurement equipment on cars (Founda, D. et al. 2015).

Since each of the aforementioned methods has its own limitations, we propose a study based on a mixed approach that combines observations in fixed representative points of the city with mobile transects along the street network; then a comparison will be made between the recorded temperature values and those measured in a nearby rural area chosen as a fixed point of reference.

\section{Data collection}

Atmospheric urban heat islands are often weak during the late morning and throughout the day and become more pronounced after sunset due to the slow release of heat from urban infrastructure. The timing of this peak depends on the properties of urban and rural surfaces, the season, and prevailing weather conditions (AквARI, H. et al. 2015). The great majority of the measurements campaigns were performed during the night, between 23:00 and 03:00 hours, but also a campaign of 24 hours of continuous measurements was conducted.

The data used in this study was collected over a period of 6 months (May-October 2015). Six different measurement campaigns were conducted, two for each season, but only one for each season was chosen to be presented in this study. In order to obtain the highest AUHI intensity, the measurements were performed mainly at higher than normal pressure conditions, clear sky, and calm weather or weak wind.

The mobile transect measurements usually lasted about 3 hours and were performed by car on three different crossing profiles with multiple stops along the routes (Figure 1). The profiles trajectories followed the main roads of the city on directions North-South, East- 


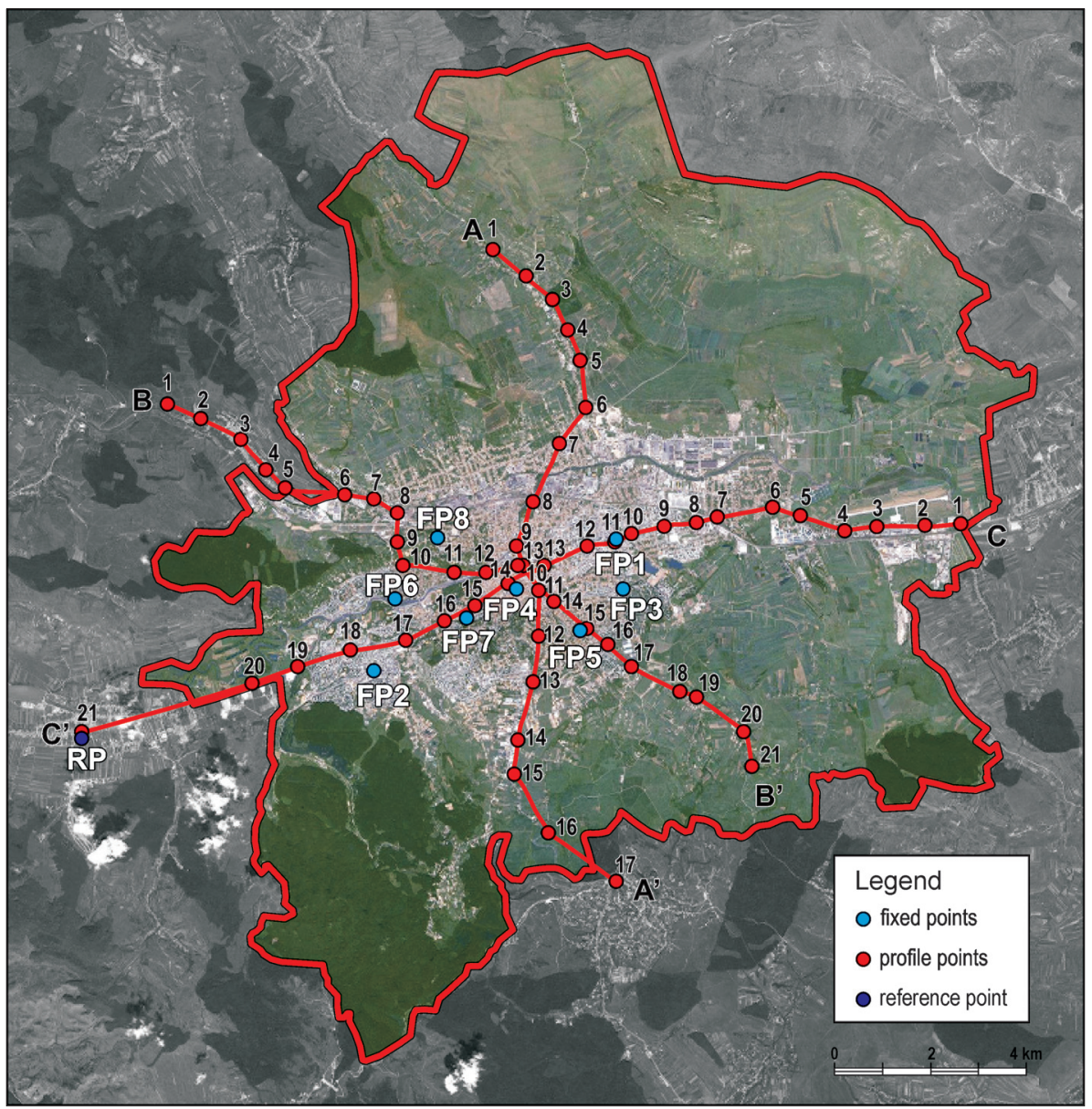

Fig. 1. Profile points, fixed points and reference point used in this study. $\mathrm{AA}^{\prime}, \mathrm{BB}^{\prime}, \mathrm{CC}^{\prime}=$ explanations are in the text

West, and Northwest-Southeast. The profile points were chosen taking into account different types of the urban tissue in the city and each profile had 17-22 measurement points.

The most representative profile for AUHI detection is $C^{\prime}$, as the altitude variation alongside is very low $(62 \mathrm{~m})$. Profile $\mathrm{AA}^{\prime}$ is the least representative due to high altitude variation along it $(380 \mathrm{~m})$ that could introduce errors in AUHI intensity when no sounding data for lapse rate are available, as is the case in Cluj-Napoca. We chose to use profile AA' because it covers few important urban fabrics and we consider that it is important to have some measurements all over the city, even though the results are not very accurate.
The temperature value was registered simultaneously every 5 minutes in the 7 fixed points located in the urban area, as well as in the fixed point in the nearby rural area.

The fixed points used for observations were chosen in order to best highlight the temperature pattern in different Local Climate Zones (LCZ) (STEWART, I.D. and OKE, T.R. 2012) generated by different urban fabric types and the nearby rural area (RP, Floreşti village). Thus, the code for the fixed points and their corresponding LCZ are listed below:

- FP1 - compact high-rise (Mărăşti Neighbourhood);

- FP2 - compact high-rise (Mănăştur Neighbourhood); 
- FP3 - compact midrise (Gheorgheni Neighbourhood);

- FP4 - compact low-rise (city centre, Old Town);

- FP5 - open low-rise (residential area: Andrei Mureşanu Neighbourhood);

- FP6 - large low-rise/water (Babeş Park/ Sports Hall/Someş River side);

- FP7 - scattered trees (park around Faculty of Geography).

In order to improve the spatial resolution of the fixed point network, we also used the data recorded in Cluj-Napoca Weather Station (WMO code: 15120), which is considered representative for sparsely built environment (FP8).

In order to perform measurements, we employed 2 automatic Davis Vantage Pro2 ${ }^{\mathrm{TM}}$ weather stations (for FP3 and FP7), 3 high precision Dostmann P400 mobile thermo-hygrometers (for mobile transects) and 9 calibrated normal (dry) meteorological thermometers. In order to avoid errors in the measurement process due to wind, a portable meteorological shelter has been used for each point, except for those with automatic weather stations. On transects the data has been collected by using both a Dostmann P400 mobile thermo-hygrometer and a normal mercury thermometer to improve the accuracy of the measurements. The geographical coordinates of each measurement point were recorded by using a GPS logger application (GPS Logger for Android).

\section{Data processing}

For data processing the procedure previously described by Herbel, I. et al. (2015) was used.

After the data was collected, the altitude corrections were performed for all the temperature values recorded in fixed and transect points, as presented in (1). The mean lapse rate used was $0.65{ }^{\circ} \mathrm{C} / 100 \mathrm{~m}$.

$$
T_{\text {Bcor }}=T_{B}+\frac{\Delta H}{100} \times 0.65,
$$

where $T_{B c o r}$ is corrected temperature in point $B$, located in the urban area (in ${ }^{\circ} \mathrm{C}$ ); $T_{B}$ is the temperature measured in point $B$, located in the urban area $\left(\right.$ in $\left.{ }^{\circ} \mathrm{C}\right)$;

$$
\Delta H=H_{B}-H_{A},
$$

where $H_{B}$ is the altitude of the point $B(\mathrm{~m})$; $H_{A}$ is the altitude of the reference point $(A)$, located in the nearby rural area (m);

In order to use the correct values of the lapse rate for altitude correction, sounding data should be used, but unfortunately this data hasn't been available for Cluj-Napoca weather stations since November 2012. Under these circumstances, we decided to use the mean lapse rate of $0.65{ }^{\circ} \mathrm{C} / 100 \mathrm{~m}$, because during spring and summer campaigns the air pressure was slightly above normal pressure.

For the temperature recorded in fixed points, only altitude corrections were performed, while for transect points a time correction was also necessary.

The primary time deviation was computed as a temperature difference between temperatures recorded in the transect point and those recorded in the reference point (RP) located in Florești village.

If the temperature values were recorded at the same time in both points (RP and point on the profile), the primary deviation was obtained using

$$
D=T_{P X}-T_{R}
$$

where $D$ is the difference to be calculated for a point $X$ (on the profile); $T_{P X}$ is the temperature measured in point $(X)$ of the profile at time $t_{x}$; and $T_{R}$ is temperature measured in $\mathrm{RP}$ at time $t_{x^{\prime}} t_{x}$ is the time when the temperature was recorded in point $X$ of the profile, given in hours and minutes.

The time corrections were computed only for those points on the profile for which the measurement time did not coincide with the one in RP.

Since the temperature value in the fixed points was collected every 5 minutes, in some cases the temperature data on the profile points was collected between two measure- 
ments in RP. In this case, the corresponding RP temperature value was obtained by adding a time correction, calculated by using formula given in (4), to the temperature measured in RP, for each profile point where the measurement time was different from the fixed point measurement time.

$$
C_{t}=\left(T_{2}-T_{1}\right) / n \times d,
$$

where $C_{t}$ is the time correction to be added to temperature recorded in $\mathrm{RP}$; the time corrected temperature is needed to get simultaneous values for the profile point and for the RP, in order to calculate the deviation between the two points; $T_{1}$ is the temperature measured in RP before the measurement in the point on the profile; $T_{2}$ is the temperature measured in RP after the measurement in the point on the profile; $n$ is number of minutes between two consecutive measurements in $\mathrm{RP} ; d$ is the number of minutes between the measurement in the profile point and the previous measurement in the RP.

After the time correction performed on the reference point value, the deviation of the profile point temperature was calculated by using (3).

\section{Results and discussion}

\section{Fixed points measurement}

\section{Spring measurements}

In spring of 2015, the chosen campaign was from May 13, 9:00 a.m. to May 14, 9:00 a.m. The measurements lasted 24 hours in the fixed points. During the data collection where the followings: the sea level pressure (SLP) was slightly above the normal values $(1,020 \mathrm{hPa})$ at the beginning of the interval and decreased below the normal values at the end of the interval. There was variable convective cloudiness, especially during daytime, covering sometimes more than 90 percent of the sky. No clouds were recorded between midnight and 3:00 a.m. Over that interval, the wind blew from Southwest with a speed lower than $2 \mathrm{~m} / \mathrm{s}$; at the end of the 24 hour interval precipitation occurred. In the second part of the night, after 4.00 a.m., a cold front affected the area with the end of its squall line, generating important temperature variations and rainfall.

The temperature values recorded in the fixed points is presented in Figure 2. The interval of relative thermal stability lasted about 5 hours (from 23:00 to 4:00). As expected, the highest temperature values were recorded in FP1 (compact high-rise), but also in FP3 (compact mid-rise), while the lowest was specific to the RP (Floressti village) and on the Somess river side (FP6). Between coolest and warmest areas, there was a difference of about $2.0^{\circ} \mathrm{C}$. The city centre is also one of the hot-spots, but more prominent in the daytime as a result of high traffic in the area.

In the night, due to low elevation buildings of the Old City, the deviation from the $\mathrm{RP}$ temperature is smaller than the one recorded for the compact high-rise and midrise LCZ.

In the daytime, high temperature variations could be observed even for the same point and the data collected in this interval was inappropriate to evaluate the AUHI intensity in Cluj-Napoca city. Therefore, for the next campaigns we focused on the night-time measurements.

\section{Summer measurements}

For summer of 2015, we chose to present here the results of the first campaign that took place between July $22^{\text {nd }}$ and July $23^{\text {rd }}$. The temperature values were collected only during the interval of relative thermal stability: 23:00-02:00 h. As general weather conditions, the SLP was slightly above normal $(1,017-1,018 \mathrm{hPa})$, there were no clouds and the wind blew with a speed of $2 \mathrm{~m} / \mathrm{s}$ from Southwest and South-Southwest.

The temperature values decreased gradually from the beginning until the end of the interval (Figure 3). The highest values were identified in FP1 (compact high-rise east), followed by FP3 (compact midrise) and FP4 (compact low-rise), while the lowest ones in the RP. In the interval of relative thermal sta- 


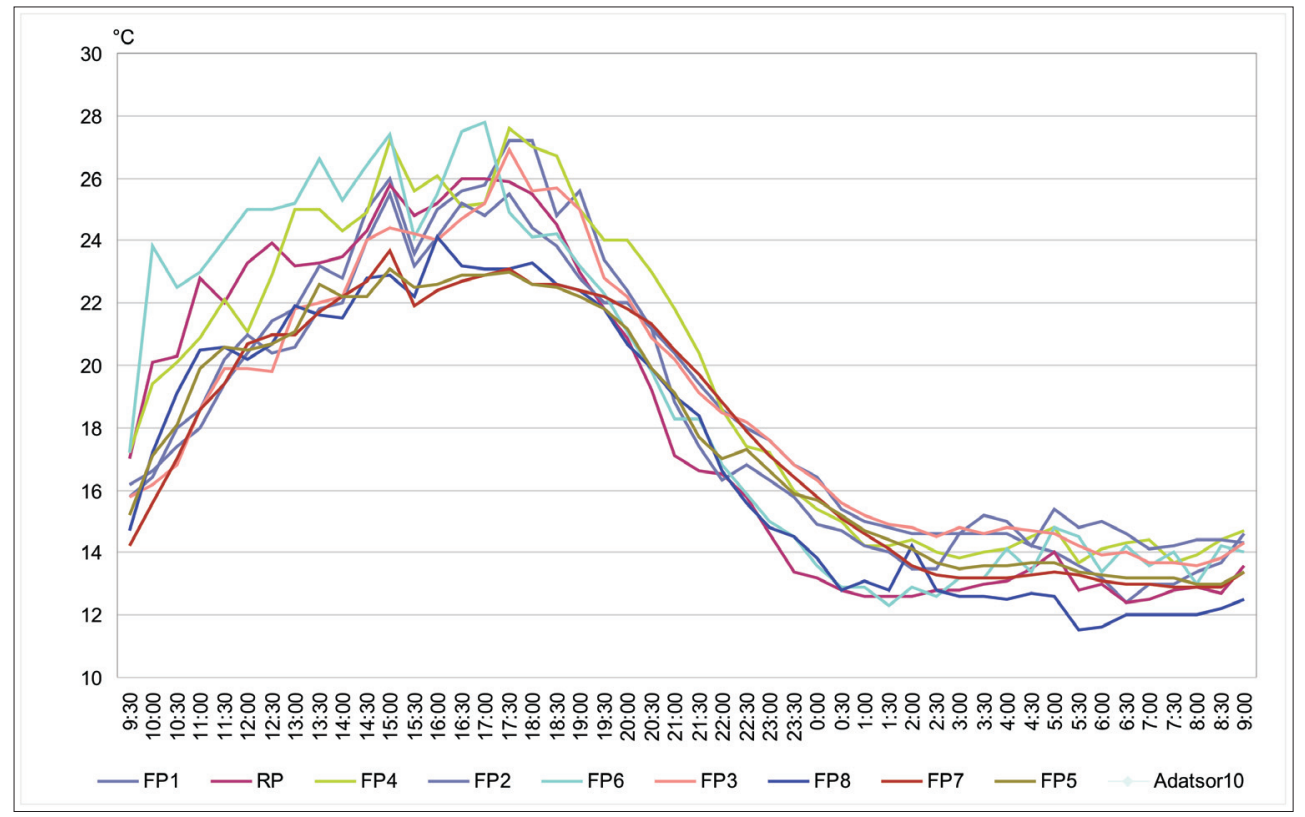

Fig. 2. Temperatures recorded in fixed points during the spring campaign (May 13-14, 2015); hours are given in local time $(\mathrm{UTC}+3.00 \mathrm{~h})$

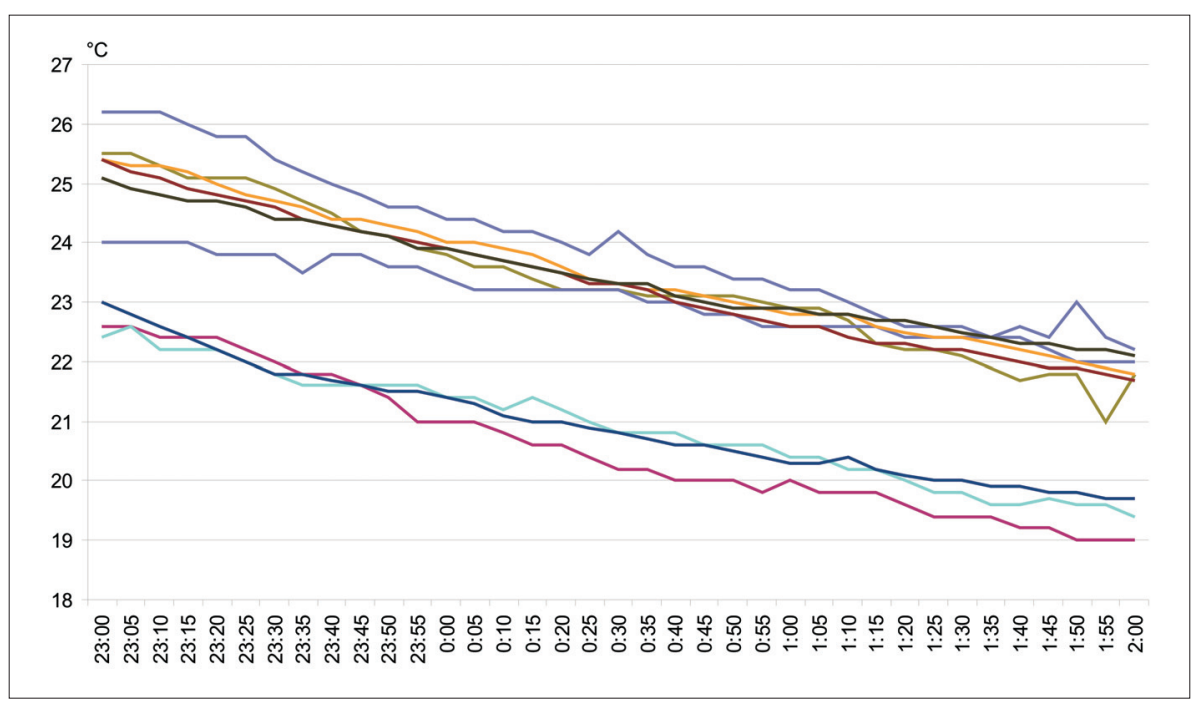

Fig. 3. Temperatures recorded in fixed points during the summer campaign (July 22-23, 2015); hours are given in local time (UTC $+3.00 \mathrm{~h})$

bility, the differences between the temperatures of the points located in the city area and $\mathrm{RP}$ varied from $0.1^{\circ} \mathrm{C}$ to $3.2^{\circ} \mathrm{C}$ as mean values, and from $-0.4{ }^{\circ} \mathrm{C}$ to $3.8^{\circ} \mathrm{C}$, in terms of extreme values (Table 1).

\section{Autumn measurements}

From the autumn measurement campaigns for AUHI analysis, we chose to present the one that started on October 24, 23:00 and ended on October 25, 2:00 am. Synoptic con- 
Table 1. Altitude corrected deviation in ${ }^{\circ} \mathrm{C}$ compared to the rural area reference point $(R P)$ by seasons

\begin{tabular}{|c|c|c|c|c|c|c|c|c|c|c|c|c|}
\hline \multirow[t]{2}{*}{ Fix points } & \multicolumn{3}{|c|}{$\begin{array}{c}\text { Spring } \\
\text { (May 13-14) } \\
\text { 9:00-9:00 h }\end{array}$} & \multicolumn{3}{|c|}{$\begin{array}{c}\text { Summer } \\
\text { (July 22-23) } \\
\text { 23:00-02:00 h }\end{array}$} & \multicolumn{3}{|c|}{$\begin{array}{c}\text { Autumn } \\
\text { (October 24-25) } \\
\text { 23:00-02:00 h }\end{array}$} & \multicolumn{3}{|c|}{ Overall } \\
\hline & Av. & Min. & Max. & Av. & Min. & Max. & Av. & Min. & Max. & Av. & Min. & Max. \\
\hline FP1- compact high-rise & 1.9 & 0.9 & 3.0 & 3.2 & 2.8 & 3.8 & 1.5 & 1.1 & 2.3 & 2.2 & 0.9 & 3.8 \\
\hline FP2 - compact high-rise & 1.5 & 0.5 & 2.3 & 2.6 & 1.5 & 3.3 & 1.2 & 0.8 & 1.6 & 1.8 & 0.5 & 3.3 \\
\hline FP3 - compact midrise & 2.1 & 0.9 & 3.0 & 2.8 & 2.5 & 3.1 & 1.3 & 0.8 & 2.0 & 2.1 & 0.8 & 3.1 \\
\hline FP4 - compact low-rise & 1.4 & 0.8 & 2.0 & 2.6 & 1.8 & 3.0 & 1.3 & 0.7 & 2.3 & 1.8 & 0.7 & 3.0 \\
\hline FP5 - open low-rise & 1.5 & 0.5 & 2.5 & 2.8 & 2.3 & 3.2 & 1.4 & 0.6 & 2.2 & 1.9 & 0.5 & 3.2 \\
\hline FP6 - large low-rise/water & -0.1 & -1.1 & 0.8 & 0.1 & -0.4 & 0.6 & 0.4 & -0.2 & 1.0 & 0.1 & -1.1 & 1.0 \\
\hline FP7 - scattered trees & 1.2 & 0.1 & 2.6 & 2.7 & 2.4 & 3.1 & 1.3 & 0.4 & 2.1 & 1.7 & 0.1 & 3.1 \\
\hline FP8 - sparsely built & 0.4 & -0.5 & 1.8 & 0.6 & 0.0 & 1.0 & -1.0 & -1.6 & -0.5 & 0.0 & -1.6 & 1.8 \\
\hline
\end{tabular}

ditions analysis revealed that an anticyclone was dominant in the area with SLP ranging from 1,023 to $1,026 \mathrm{hPa}$. During the measurements, the cloudiness varied from 80 percent at the beginning of the measurements, to no clouds at the end of the interval. The wind blew from Southwest and South-southwest with an average speed of $2 \mathrm{~m} / \mathrm{s}$.

The temperature decreased slowly over the interval (Figure 4). The highest temperature values were registered, as in the other measurement campaigns, in FP1 (compact high-rise-east) but overall, the differences between the observation points from the urban area and the RP were smaller than in summer. In FP8 (the sparsely built type), the temperature was lower than in RP, with an average deviation of $-1.0^{\circ} \mathrm{C}$. The difference between the warmest point (FP1) and RP was smaller at the beginning $\left(1.1^{\circ} \mathrm{C}\right)$, due to high cloudiness, reaching $2.3^{\circ} \mathrm{C}$ at the end of the interval. The mean deviation recorded in FP1 was $1.5{ }^{\circ} \mathrm{C}$ (Table 1$)$.

It is worth mentioning that we chose two fixed points in different compact high-rise areas with different local air circulation. The first one (FP1), located in the eastern part of the city proved to be constantly the warmest area in the city, situation that corresponds to any theoretical approach. The second one (FP2), located in the western part of the city, is directly exposed to the mountain night breeze blowing over the city from West and Southwest. The cool air descends from Western Carpathians with an almost constant velocity of $2 \mathrm{~m} / \mathrm{s}$ and it is the most common wind blowing over the city in the night-time, transporting the warmer air eastward. This is the explanation for the fact that the western compact high-rise area is cooler than the eastern one. During our campaigns we recorded temperature differences ranging from $0.4^{\circ} \mathrm{C}$ to $1.3{ }^{\circ} \mathrm{C}$ between the two compact high-rise areas.

\section{Profile measurements}

\section{AA' Profile}

The first profile used in this study extends from the northern part of the study area to the southern part over a distance of $15 \mathrm{~km}$ (Figure 1) and the temperature was measured in 17 points. Due to the topography of the city, the altitude of the points ranges from $400 \mathrm{~m}$ to higher than $700 \mathrm{~m}$. It is the only profile with such an important altitude difference. The presence of the altitude difference makes this profile the least representative one, as presented at data collection. We should note that the use of the altitude corrections may lead to false UHI intensities in the area of higher altitudes and under these conditions we should be very cautious in interpreting the data. Therefore, we focused more on the segment between points 6 and 14 , where the altitude variation was quite small. As can be seen in Figure 1, the first five and the last three points of the profile are located outside the built area of the city.

The seasonal variation of real time deviation on $\mathrm{AA}^{\prime}$ Profile compared to the nearby 


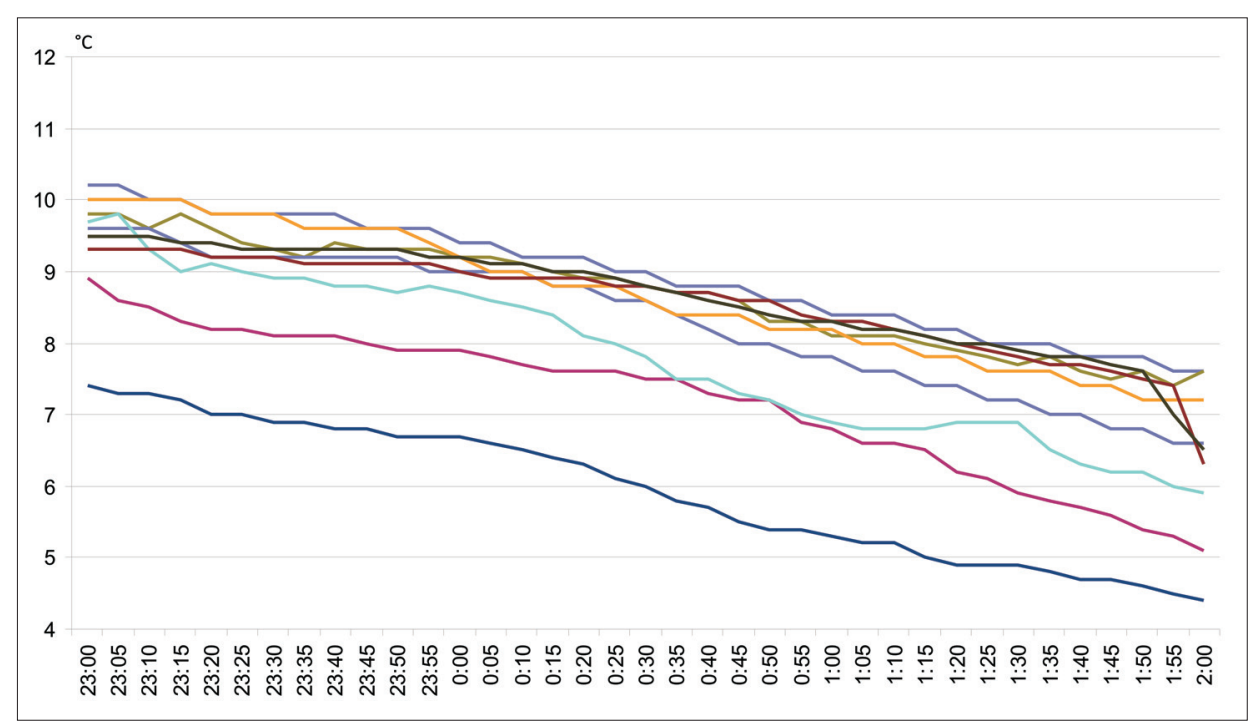

Fig. 4. Temperatures recorded in fixed points during the autumn campaign (October 24-25, 2015); hours are given in local time $(\mathrm{UTC}+3.00 \mathrm{~h})$

rural area is shown in Figure 5. The final (southern) part of the profile was usually characterized by thermal inversions.

The shape of the AUHI can only be observed in the first part of the route for the spring and summer measurements. In autumn, thermal inversion occurred at higher altitude. If we ignore the increased temperature values induced by thermal inversions due to the topography and to the weather conditions (and not by the urbanization process) at the last three points of the route, the highest intensity of the AUHI could be observed in the summer (with deviation varying up to $3.0^{\circ} \mathrm{C}$ ), followed by spring (up to $2.0^{\circ} \mathrm{C}$ ), and autumn (up to $1.5^{\circ} \mathrm{C}$ ).

\section{2. $B B^{\prime}$ Profile}

The second profile has a length of $18 \mathrm{~km}$ (Figure 1) and lower altitude variations compared to the first one. The average altitude of the profile points is $350 \mathrm{~m}$, except the two final (South-East) points where the altitude increases to more than $450 \mathrm{~m}$. This altitude difference is also associated to thermal inversion phenomena developed between the southern high hills and the city area. They generate higher temperature deviations compared to RP at the end of the route (Figure 6) for the campaigns conducted in May and July. The AUHI on BB' profile can be clearly identified in spring and summer, but not in October, when the temperature recorded in the central part of the city was not much higher compared to that measured in the rural area.

In terms of AUHI intensity on this profile, the highest deviation occurred in the summer with a value reaching up to $3.0^{\circ} \mathrm{C}$ in the central area of the city, while the lowest was recorded in the spring (up to $1.3^{\circ} \mathrm{C}$ ).

\section{CC' Profile}

The third route is the most representative for AUHI detection as it has the lowest altitude variations among the points, of only 80 $\mathrm{m}$. The altitude along the profile ranges from $300 \mathrm{~m}$, in the first point of the profile, to 380 $\mathrm{m}$ (ASL) in the final point which coincided with the RP.

CC' Profile extends over $20 \mathrm{~km}$ along the most important road trajectory of the city (from East to West), from Cluj-Napoca airport to the RP (Figure 1). Its trajectory intersected three fixed points located in the 
eastern compact high-rise area (PF1), the compact low-rise area (PF4), and the rural area (RP). Under these circumstances, we used this route also as a quality control of the data measured in the fixed points.

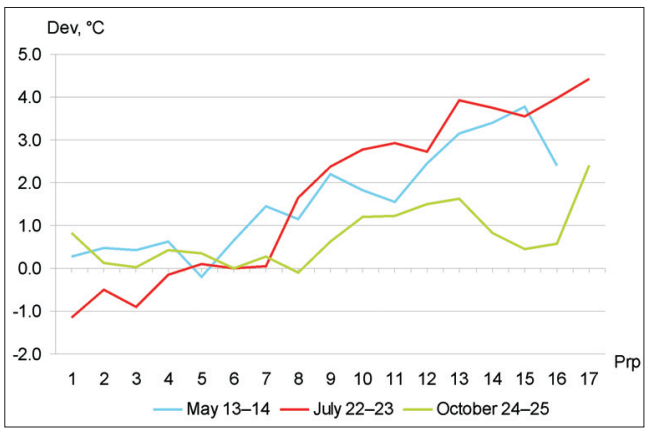

Fig. 5. Temperature deviation compared to RP along $\mathrm{AA}^{\prime}$ profile. Dev = deviation; $\operatorname{Prp}=$ profile point

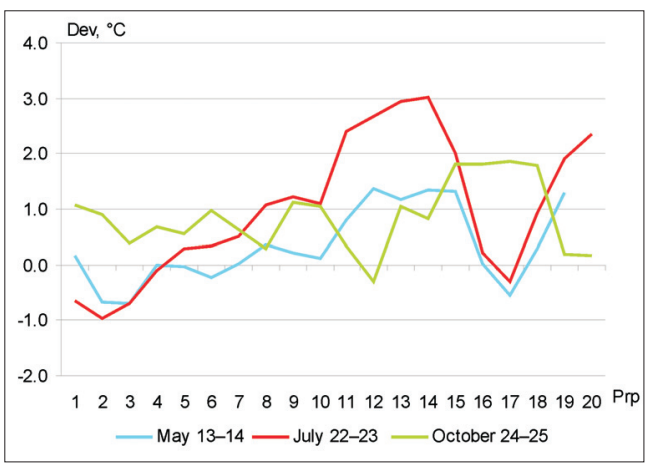

Fig. 6. Temperature deviation compared to RP along $\mathrm{BB}^{\prime}$ profile. Dev = deviation; $\operatorname{Pr} \mathrm{p}=$ profile point

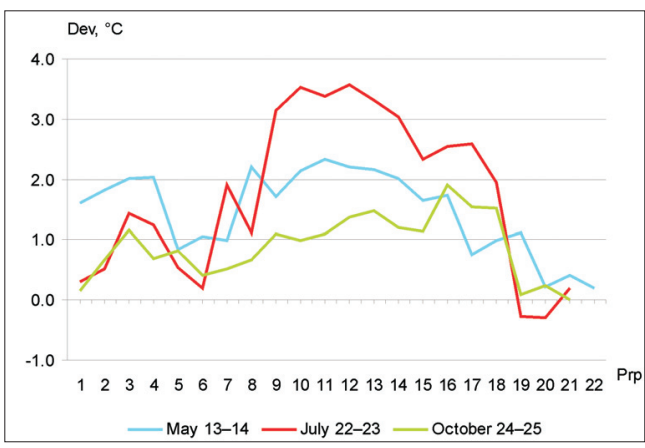

Fig. 7. Temperature deviation compared to RP along $\mathrm{CC}^{\prime}$ profile. $\mathrm{Dev}=$ deviation; $\operatorname{Prp}=$ profile point
The AUHI can be very well emphasized on this profile (Figure 7) for all seasons considered, but the values for summer are the highest, with more than $3.5^{\circ} \mathrm{C}$ in the eastern compact high-rise area.

During the campaign conducted in autumn, the most significant deviation could be observed on the second half of the route, denoting the presence of a thermal inversion, as the altitude sharply increases between points 15 and 17.

The high values from the beginning of each $\mathrm{CC}^{\prime}$ profile correspond to "Avram Iancu" International Airport area (point 3 is in the very front of the airport), which became urbanized enough in the last decade to be considered as a non-rural area. Points 5 and 6 on this profile are located in an open field area, as well as points 19 and 20. The temperature differences recorded in those two similar areas (open field) can be also explained by the air circulation (night breeze), which transports the warm air from the city to the eastern-northeastern areas.

\section{Conclusions}

The analysis of direct observations performed in three seasons (spring, summer, and autumn) revealed the existence of an AUHI in Cluj-Napoca city.

The warmest areas are compact high-rise and compact midrise areas located in the eastern half of the city, where the temperature increases by more than $2{ }^{\circ} \mathrm{C}$, as average value for all campaigns, but the maximum values, recorded in summer are more than $3{ }^{\circ} \mathrm{C}$ higher. They are followed by compact high-rise areas located in the western part of the city, compact and open low-rise and scattered trees areas, where the temperature as an overall average is $1.7-1.9^{\circ} \mathrm{C}$ higher, while the coolest areas are the sparsely built and the large low-rise/water areas, where the temperature is quite similar to that recorded in the nearby rural area (deviations from the $\mathrm{RP}$ are between $0.0-0.1^{\circ} \mathrm{C}$, as average values) (Table 1). 
The profile measurements also emphasized the AUHI dome, for all the campaigns.

Local factors, such as air circulation (mountain breeze descending from Western Carpathians) and topography have a great importance to AUHI configuration. Thus, usually, due to mountain breeze the AUHI at night is elongated eastward, and sometimes isothermia or even thermal inversions can be identified.

Acknowledgements: This work was partially supported by the Sectorial Operational Program for Human Resources Development 2007-2013, co-financed by the European Social Fund, under the project number POSDRU/159/1.5/S/132400 titled Young successful researchers - professional development in an international and interdisciplinary environment.

\section{REFERENCES}

Akbari, H., Bell, R., Brazel, T., Cole, D., Estes, M., Heisler, G., Hitchсock, D., Johnson, B., Lewis, M., McPherson, G., Oke, T.R., Parker, D., Perrin, A., Rosenthal, J., Sailor, D., Samenow, J., Taha, S., Voogt, J., Einter, D., Wolf, K. and Zalph, B. 2016. Reducing Urban Heat Islands: Compendium of Strategies. Urban Heat Island Basics, www.epa.gov.

Akbari, H., Cartalis, C., Kolokotsa, D., Muscio, A., Pisello, A.L., Rossi, F., Santamouris, M., Synnefa, A., Wong, N.H. and ZinZI, M. 2015. Local climate change and urban heat island mitigation techniques - The state of the art. Journal of Civil Engineering and Management 22. (1): 1-16.

Apostol, L., Alexe, C. and Sfîcă, L. 2012. Thermic differenciations in the Iasi Municipality during a heat wave. Case study July 10-20 2011. Present Environment and Sustainable Development 6. (1): 395-404.

Charabi, Y. and Bakhit, A. 2011. Assessment of the canopy urban heat island of a coastal arid tropical city: the case of Muscat, Oman. Atmospheric Research 101. 215-227.

Cheval, S. and Dumitrescu, A. 2009. The July urban heat island of Bucharest as derived from MODIS images. Theoretical and Applied Climatology 96. (1-2): 145-153.

Cheval, S. and Dumitrescu, A. 2015. The summer surface urban heat island of Bucharest (Romania) retrieved from MODIS images. Theoretical and Applied Climatology 121. 631-640.

Cheval, S., Dumitrescu, A. and Bell, A. 2009. The urban heat island of Bucharest during the extreme high temperatures of July 2007. Theoretical and Applied Climatology 97. 391-401.

Cohen, B. 2006. Urbanization in developing countries: Current trends, future projections, and key challenges for sustainability. Technology in Society 28. (1-2): 63-80.

ERHAN, E. 1971. Climatic differentiations in the urban and surrounding area of Iaşi city. Lucrări Ştiințifice Seria Geografie. Oradea, Institutul Pedagogic Oradea.

ERHAN, E. 1979. Climate and microclimates in the area of Iaşi city. Iaşi, Junimea.

European Environment Agency (EEA) 2010. European environment state and outlook 2010: urban environment. SOER Report. 228 p.

Founda, D., Pierros, F., Petrakis, M. and Zerefos, C. 2015. Interdecadal variations and trends of the Urban Heat Island in Athens (Greece) and its response to heat waves. Atmospheric Research 161-162. 1-13.

Gartland, L. 2008. Understanding and mitigating heat in urban areas. London, Earthscan.

Giannaros, T.M. and Melas, D. 2012. Study of the urban heat island in a coastal Mediterranean City: the case study of Thessaloniki, Greece. Atmospheric Research 118. 103-120.

Grubler, A., Bai, X., Buettner, T., Dhakal, S., Fisk, D.J., Ichinose, T. and Weisz, H. 2012. Chapter 18 Urban Energy Systems. In Global Energy Assessment - Toward a Sustainable Future. International Institute for Applied Systems Analysis. Laxenburg, Austria, Cambridge, UK and New York, Cambridge University Press, 1307-1400.

Gugiuman, I. 1967. A few problems regarding the climatology of the cities in Romania. ASUCI - GG, Section II, XIII, 27-32.

Herbel, I., Croitoru, A.E., Imbroane, A.M. and PetreA, D. 2015. Methods to detect atmospheric and surface heat islands in urban areas. Riscuri şi catastrofe 17. (2): 25-32.

Hu, L., Monaghan, A.J and Brunsell, N.A. 2015. Investigation of urban air temperature and humidity patterns during extreme heat conditions using satellite-derived data. Journal of Applied Meteorology and Climatology 54. (11): 2245-2259.

Imbroane, A.M., Croitoru, A.E., Herbel, I., Rus, I. and Petrea, D. 2014. Urban heat island detection by integrating satellite image data and GIS techniques. Case study: Cluj-Napoca city, Romania. In Proceedings of the $14^{\text {th }}$ International Multidisciplinary Scientific Geoconference SGEM 2014, 17-26 June. Albena, Bulgaria, 359-366.

Katsoulis, B.D. and Theoharatos, G.A. 1985. Indications on the Urban Heat Island in Athens, Greece. Journal of Climate and Applied Meteorology 24. 1296-1302.

Kumar, D. and Shekhar, S. 2015. Statistical analysis of land surface temperature - vegetation indexes 
relationship through thermal remote sensing. Ecotoxicology and Environmental Safety 121. 39-44.

Lelovics, E., Unger, J., Gál, T. and Gál, C.V. 2014. Design of an urban monitoring network based on Local Climate Zone mapping and temperature pattern modelling. Climate Research 60. 51-62.

LI, J., WANG, X., WANG, X., MA,W. and ZhanG, H. 2009. Remote sensing evaluation of urban heat island and its spatial pattern of the Shanghai metropolitan area, China. Ecological Complexity 6. (4): 413-420.

Memon, R.A., Leung, D.Y.C. and LiU, C.H. 2008. A review on the generation, determination and mitigation of urban heat island. Journal of Environmental Sciences-China 20. (1): 120-128.

Santamouris, M. 2007. Heat island research in Europe - the state of the art. Journal Advances in Building Energy Research 1. 123-150.

Santamouris, M. 2015. Analyzing the heat island magnitude and characteristics in one hundred Asian and Australian cities and regions. Science of the Total Environment 512-513, 582-598.

Seto, K.C., Guneralp, B. and Hutyra, L.R. 2012. Global forecasts of urban expansion to 2030 and direct impacts on biodiversity and carbon pools. Proceedings of the National Academy of Sciences of the United States of America 109. 16083-16088

Shepherd, J.M. and Burian, S.J. 2003. Detection of urban-induced rainfall anomalies in a major coastal city. Earth Interactions 7. (4): 1-17.

Song, X.P., Sexton, J.O., Huang, C., Channan, S. and Townshend, J.R. 2016. Characterizing the magnitude, timing and duration of urban growth from time series of Landsat-based estimates of impervious cover. Remote Sensing of Environment 175. 1-13.
Stewart, I.D. 2011. A systematic review and scientific critique of methodology in modern Urban Heat Island literature. International Journal of Climatology 31. (2): 200-217.

STEWART, I.D. and OKe, T.R. 2012. Local Climate Zones for urban temperature studies. Bulletin of American Meteorological Society 93. (12): 1879-1900.

TAN, J., Zheng, Y., TANG, X., Guo, C., Li, L., Song, G., Zhen, X., Yuan, D., Kalkstein, A.J., LI, F. and Chen, H. 2010. The urban heat island and its impact on heat waves and human health in Shanghai. International Journal of Biometeorology 54. 75-84.

Unger, J., SAvić, S., GáL, T. and Milošević, D. 2014. Urban Climate and Monitoring Network System in Central European Cities. Novi Sad-Szeged, University of Novi Sad, Faculty of Sciences (UNSPMF) and University of Szeged, Department of Climatology and Landscape Ecology (SZTE), 101 p.

Unger, J., Sümeghy, Z., Szegedi, S., Kiss, A. and Géczi, R. 2010. Comparison and generalisation of spatial patterns of the urban heat island based on normalized values. Physics and Chemistry of the Earth 35. 107-114.

United Nations 2014. World Urbanization Prospects: The 2014 Revision. New York: United Nations. http://esa.un.org/unpd/wup/Highlights/WUP2014Highlights.pdf.

Wilby, R.L. 2007. A review of climate change impacts on the built environment. Built Environment 14. 31-45.

Wong, K.V., Paddon, A. and Jimenez, A. 2013. Review of world urban heat islands: Many linked to increased mortality. Journal of Energy Resources Technology 135. (2): 022101-022112. 